\title{
Variability of Stability, Momentum and Heat Fluxes in the Stable Boundary Layer over Highveld Priority Area, South Africa
}

\author{
Philbert M. Luhunga ${ }^{1} \&$ Edmund Mutayoba ${ }^{2}$ \\ ${ }^{1}$ Tanzania Meteorological Agency, Research Section, Dar Es Salaam Tanzania \\ ${ }^{2}$ Mbeya University of Science and Technology, P.O. BOX 131, Mbeya \\ Correspondence: Philbert M. Luhunga, Tanzania Meteorological Agency, Research Section, P.O. BOX 3056, Dar \\ Es Salaam, Tanzania. E-mail: philuhunga@yahoo.com
}

Received: August 11, 2011 Accepted: November 13, $2011 \quad$ Online Published: July 9, 2013

doi:10.5539/apr.v5n4p23 URL: http://dx.doi.org/10.5539/apr.v5n4p23

\begin{abstract}
In this paper, we present the micro-spatial scale and temporal variability of Obukhov length (L), Kinematic momentum flux or turbulent friction velocity $\left(u_{*}\right)$ and heat flux $\left(\theta_{*}\right)$ in the Stable Boundary Layer (SBL) using observational data collected by a dense network of five Automatic Weather Stations (AWSs). The stations were in operation in the Highveld Priority Area (HPA) of the Republic of South Africa during 2008-2010. The L, $u_{*}$ and $\theta_{*}$ are solved using Monin Obukhov similarity theory. Analysis of spatial variability of stability regimes as presented by L suggests that HPA is dominated by strong stability regime. The analysis also revealed inter-station variability of $\theta_{*}$ and $\mathrm{L}$ while $u_{*}$ indicates no significant spatial variability between stations. Temporal variability showed that most of the low values for Obukhov length that fall within strong stable regimes $(0<\mathrm{L}<16)$ occurs at night. Almost $30-50 \%$ of $u_{*}$ in the range of $0<u_{*}<0.2, \theta_{*}$ in the range of $0<\theta_{*}<0.8$ and $\mathrm{L}$ in the range of $0<L<16$ occurs around 15-18 and 18-21 hours, local time (GMT+2) and about 5-10\% occurs around 6-15 hours, local time $(\mathrm{GMT}+2)$. These observations suggest that radiative cooling and stability are stronger in the night than day time SBL and the momentum fluxes are weaker in the night than day time SBL. Finally it is found that temporal inter-station variability of $\mathrm{L}, u_{*}$ and $\theta_{*}$, could play a significant role on diffusion and dispersion of tracers and contaminant and influence on local air quality at hourly to diurnal scales in the SBL.
\end{abstract}

Keywords: micro-meteorology, stable atmospheric boundary layer, air pollution

\section{Introduction}

The Atmospheric Boundary Layer (ABL) is the part of the troposphere in which we live and carry out most of human activities, it is also known as Planetary Boundary Layer (PBL) or simply Boundary Layer (BL). In this layer significant fluxes of momentum, heat or matter are carried by turbulent motions on a scale of order of the depth of the BL or less (Stull, 1988). ABL is very important in atmospheric studies since it plays a significant role on the dynamic state of the entire atmosphere. More than $95 \%$ of the solar energy is received at the lower part of the $\mathrm{ABL}$ where it is transformed and transmitted to different parts of the atmosphere by different processes occurring in the ABL, such as turbulent mixing and molecular diffusion.

$\mathrm{ABL}$ is usually classified into three types: neutral/Residual, convective and stable stratifications based on atmospheric stability and the dominant mechanism of turbulence generation. It is stably classified whenever the underlying surface is colder than the air above it (Steeneveld \& Coauthors, 2008).

The Stable Boundary Layer (SBL) is very complex in its behaviour. It is characterized by turbulence discontinuity in space and time. On clear nights with weak winds, a frequently observed phenomenon is weak and intermittent character of turbulence. Intermittent turbulence is characterized by brief episodes of turbulence with intervening periods of relative weak or immeasurable small fluctuations (Garratt, 1992). The intermittent behaviour of turbulence causes alternations from the mean evolution of the stratified ABL. As a result of deviation from the mean evolution of stratified ABL, the near surface atmospheric variables such as temperature, wind and humidity will have an oscillatory type of behaviour. This is the manifestation of the non-linear character of the turbulent exchange in the SBL. The oscillatory behaviour of near-surface atmospheric variables in the SBL has a significant effect on local air quality at hourly to diurnal scales.

Meteorology of the Highveld has been intensively studied (e.g. Von Gogh et al., 1982; Tyson et al., 1988; Jury \& 
Tosen, 1989; Held et al., 1996; Scheifinger \& Held, 1997; Freiman \& Tyson, 2000; Tyson \& Gatebe, 2001; Tennant \& Hewitson, 2002; Freiman \& Piketh, 2003; Thomas et al., 2007; Collett et al., 2010; Laakso et al., 2010) but there is still need for further experimentation and theoretical analysis to understand the SBL process. Furthermore in none of these publications experimental or theoretical research is done on characterizing the turbulent fluxes which are responsible for the structure and dynamics of the entire SBL. The aim of this paper is to characterise the micro-spatial scale and temporal variability of Obukhov length (L), momentum and heat fluxes in the Stable Boundary Layer (SBL) over Highveld region of South Africa. This region contains most of the coal-power generating plants of South Africa. The understanding of SBL micro- spatial scale and temporal variability of Obukhov length (L), momentum and heat fluxes provides useful results for improved accuracy of dispersions and weather or climate prediction models since the contemporary NWP, climate models still do not resolve the dynamics of SBL due to its complexity and due to the lack of high resolution models.

\section{Data and Analysis}

\subsection{Description of the Study Area}

\subsubsection{Geography}

The HPA is located in the South Africa Highveld region $\left(25^{\circ} \mathrm{S}\right.$ to $27^{\circ} \mathrm{S} ; 28^{\circ} \mathrm{E}$ to $\left.30^{\circ} \mathrm{E}\right)$. It extends across parts of Gauteng and Free State provinces to the East of the highly urbanized Gauteng Province including the largest cities Pretoria and Johannesburg, and occupies area of about $30000 \mathrm{~km}^{2}$ at about $1400 \mathrm{~m}-1700 \mathrm{~m}$ above sea level The surface of the plateau over Highveld region is rather flat but its morphology is very heterogeneous. At small spatial scales, depressions and hills could be found with the elevation difference of 10-20 m and the typical elevation gradients of 5-10 $\mathrm{m} \mathrm{km}^{-1}$ (Esau et al., 2010).

About $70 \%$ of the Highveld area is covered by grassland and the rest is utilized for agricultural (maize, cattle and sheep, and crop production), urban and industrial activities. This area is associated with poor air quality and elevated concentrations of criteria pollutants occur due to the concentration of industrial and non industrial sources (Held et al., 1996; Scheifinger \& Held, 1997). Figure 1 exemplifies the surface heterogeneity. It shows the normalized digital vegetation index (NDVI) for $20 \mathrm{~km}$ by $20 \mathrm{~km}$ patch within the Highveld obtained from the Landsat platform 7 satellite on 22. February 2007. Typical elements of the surface heterogeneity in Figure 1 are seen as green and yellow patches-agricultural fields (wheat and maize); gray and black patches-coal transporter; blue patches-water reservoirs; magenta patches - build-up areas; and reddish and greyish patches-natural bush and harvested fields.

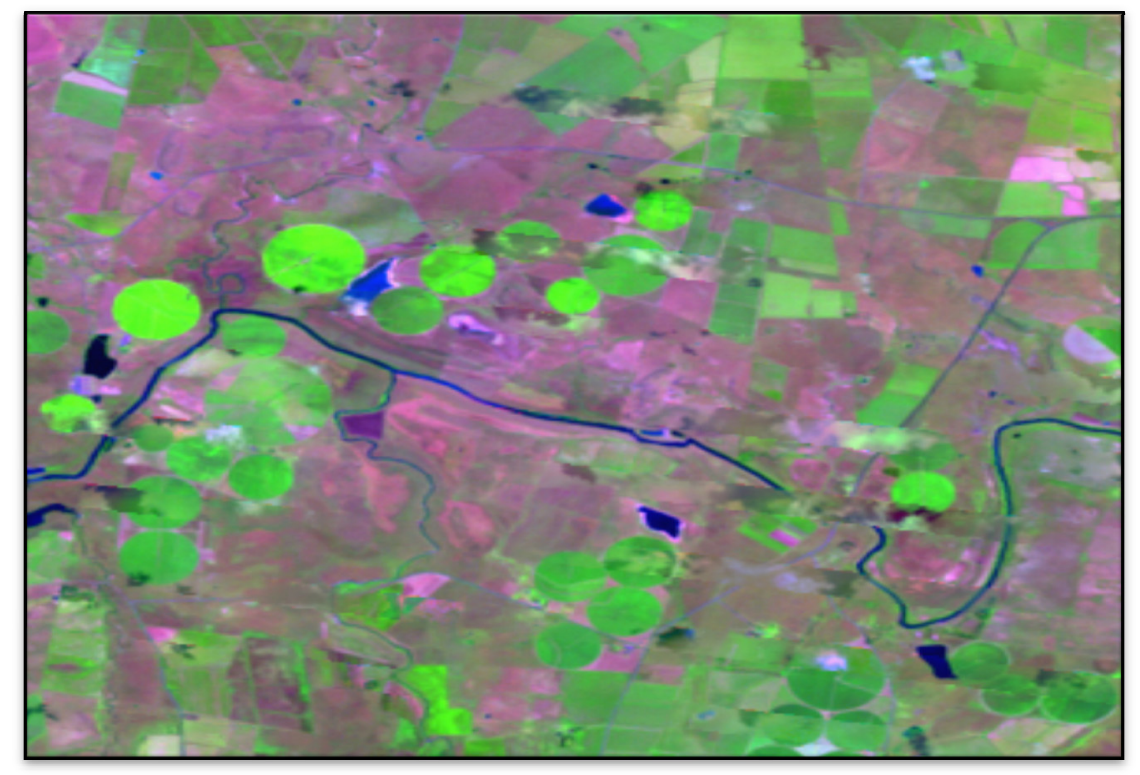

Figure 1. Surface heterogeneity over Highveld region detected using normalized digital vegetation index (NDVI) for the tile e29s27 obtained by the Landsat platform 7 with the sensor ETM+ at 22 February 2007. Data source is FAO FRA Landsat Imagery Database http://globalmonitoring.sdstate.edu/projects/fao/index.html 


\subsubsection{Climate of the Region}

Over South Africa as a whole, and Highveld in particular, the general circulation of the atmosphere is anti-cyclonic throughout the year above 700 hpa (Esau et al., 2012). In summer season, surface radiation facilitates the development of near-surface troughs in the region, dominated by upper air subsidence. On the synoptic-scale clockwise circulation around these troughs lead to moisture advection from the tropics which is a major contributor to summer rains when local instabilities often lead to the development of convective thunderstorms (Esau, 2012). In dry winter season the anti-cyclonic circulation dominates throughout the entire troposphere (Jury \& Tosen, 1989). A ridging high pressure that extends from the Atlantic High pressure system and propagates eastwards along the South African coastline, behind a cold front might result in moisture advection from south-east and cloud development against the eastern escarpment of the Highveld (Esau, 2012). The Highveld region climate is cooler than climate of other areas of similar latitude, which is mainly due to the Highveld high altitude. Highveld weather is characterized by hot summer daytime temperatures $\left(25\right.$ to $\left.32{ }^{\circ} \mathrm{C}\right)$ and frequent late afternoon thundershowers. Winter daytime average temperatures ranges from 15 to $19{ }^{\circ} \mathrm{C}$, but night time temperatures often drop below freezing and morning frost is common.

\subsection{Data}

The data used in this study were sampled continuously from 01.01. 2008 to 30.12.2010 using 5 Davis Automatic Weather stations (DAWS) deployed in the Highveld Priority Area (HPA). Figure 2 shows the locations of the automatic meteorological station network in this area. In total, 5 stations were placed on farmers' land, mostly at the edge of agricultural (maize) fields. The station placing is not ideal due to practical security reasons and logistics that have to be taken into account. Some stations are located close to some low buildings, farmer houses and wire fences, which may contaminate the collected data (Esau et al., 2010). Table 1 lists the meteorological stations and their geographic coordinates. Table 2 gives the geodetic distances between the stations. The experimental set up for the observation of all relevant meteorological variables and data collection are presented in (Esau et al., 2010). The stations use a combination of fan-aspiration and passive shielding to minimize the effects of solar radiation-induced temperature error. It should be noted that in addition to the Davis station experimental set up, which was mounted at height of $2 \mathrm{~m}$, one more temperature sensor has been installed at 0.5 $\mathrm{m}$ to allow for calculation of turbulent fluxes.

Table 1. The list of automatic meteorological stations, their coordinates, altitudes and completeness of the data in the database

\begin{tabular}{|c|c|c|c|c|c|c|}
\hline Station and farm name & $\begin{array}{l}\text { Latitude } \\
\text { (S) }\end{array}$ & $\begin{array}{l}\text { Longitude } \\
\text { (E) }\end{array}$ & $\begin{array}{l}\text { Altitude } \\
\text { (m) }\end{array}$ & Completeness (\%) & Completeness (\%) & Completeness (\%) \\
\hline & & & & \multirow{2}{*}{ 01.01.08-31.12.10 } & \multirow{2}{*}{ 01.06.09-31.07.09 } & 01.01.09-28.02.09 \\
\hline & & & & & & 01.01.10-31.07.10 \\
\hline S1. Jan de Jager, Banklaagte & 26.405 & 29.569 & 1650 & 19 & 80 & 70 \\
\hline $\begin{array}{c}\text { S2. Anton } \\
\text { VanTonder,Yzervarkfontein }\end{array}$ & 26.370 & 29.455 & 1660 & 19 & 0 & 70 \\
\hline S3. Bram Jordan, Rietkuil & 26.286 & 29.616 & 1670 & 15 & 0 & 0 \\
\hline S4. Anton Pelse,Driefontein & 26.089 & 29.566 & 1706 & 50 & 100 & 100 \\
\hline $\begin{array}{l}\text { S5. DaleenvonWieligh, } \\
\text { Bultfontein }\end{array}$ & 26.127 & 29.499 & 1656 & 18 & 0 & 0 \\
\hline
\end{tabular}

Table 2. Distances (in km) between the Davis Automatic Weather Station (DAWS) (S)

\begin{tabular}{llcccc}
\hline & S1 & S2 & S3 & S4 & S5 \\
\hline S2 & 12 & - & - & - & - \\
S3 & 14 & 19 & - & - & - \\
S4 & 35 & 33 & 23 & - & - \\
S5 & 32 & 27 & 21 & 8 & - \\
\hline
\end{tabular}


Table 3. Percentage of wind velocity bigger than 6 and less than $6 \mathrm{~m} / \mathrm{s}$ at different stations

\begin{tabular}{ccc}
\hline Stations & $\%$ wind $>6 \mathrm{~m} / \mathrm{s}$ & $\%$ wind $<6 \mathrm{~m} / \mathrm{s}$ \\
\hline S1 & 0 & 100 \\
S2 & 1 & 99 \\
S3 & 6 & 94 \\
S4 & 0 & 100 \\
S5 & 0 & 100 \\
\hline
\end{tabular}

\subsection{Methodology}

In this study the calculation of turbulent friction velocity, sensible heat fluxes and Obukhov length is based on similarity theory. First, for the past already 60 years Kolmogorov's (Kolmogorov, 1941) approach for turbulent closure models based on the turbulent kinetic energy (TKE) balance has been a major scientific tool. His hypothesis, however, is theoretically only justified for neutrally stratified turbulent flows. Many attempts to apply Kolmogorov's method for stratified flows have encountered difficulties. The straightforward application of the TKE budget equation leads to the existence of critical Richardson number above which the turbulence is suppressed.

The Kolmogorov's theory for turbulence laid the foundation of the similarity theory developed by Monin-Obukhov (MO) (Monin \& Obukhov, 1954). This theory extended the results for neutrally stratified turbulent flow to any stratification conditions. The similarity theory postulates that near any given surface, the wind and thermodynamic profiles should be determined purely by the height $z$ above the surface (which scales the eddy size) and the surface turbulent fluxes which drive turbulence: surface momentum flux which is often expressed as friction velocity $u_{*}=\left[\left(\overline{\left(u^{\prime} w^{\prime}\right)_{s}}\right)^{2}+\left(\overline{\left(v^{\prime} w^{\prime}\right)_{s}}\right)^{2}\right]^{\frac{1}{2}}$, surface buoyancy flux $F_{s}=\overline{\left(w^{\prime} b^{\prime}\right)_{s}}$ and the buoyancy parameter $\beta=g / T_{0}$ ( $g$ is the gravity acceleration, $T_{0}$ is a reference temperature of absolute temperature). From these dimensional parameters one can construct the Obukhov length described by:

$$
L=\frac{-u_{*}^{3}}{\kappa F_{s}}=\frac{-\tau^{3 / 2}}{\kappa F_{s}}, \text { or } L=\frac{u_{*}^{2}}{\kappa^{2} \beta \vartheta_{*}}
$$

Where $\kappa$ is the Von Karman constant. $L$, is positive for stable and negative for unstable boundary layers. In the ABL, a typical $u_{*}$ is $0.3 \mathrm{~ms}^{-1}$ and a typical range of buoyancy flux would be $-3 \times 10^{-4} \mathrm{~m}^{2} \mathrm{~s}^{-3}$ (night time) to $1.5 \times 10^{-2} \mathrm{~m}^{2} \mathrm{~s}^{-3}$ (midday) (i. e. a virtual heat flux $-10 \mathrm{Wm}^{-2}$ at night, $500 \mathrm{Wm}^{-2}$ at midday), giving $L=200 m$ (night time) and $-5 m$ (midday) (Bretherton, 2011).

One can form a single non dimensional stability parameter:

$$
\zeta=\frac{z}{L}
$$

According to MO similarity theory, the flux-profile gradient relationship for momentum and potential temperature are given by:

$$
\begin{gathered}
\frac{k z}{\tau_{*}^{1 / 2}} \frac{\partial \bar{u}}{\partial z}=\left(\frac{k z}{u_{*}}\right) \frac{d \bar{u}}{d z}=\Phi_{m}(\zeta) \\
\frac{k_{\theta} z \tau_{*}^{1 / 2}}{F_{\theta}} \frac{\partial \theta}{\partial z}=\left(\frac{k z}{\theta_{*}}\right) \frac{\mathrm{d} \bar{\theta}}{\mathrm{dz}}=\Phi_{\theta}(\zeta)
\end{gathered}
$$

where $\Phi_{m}(\varsigma)$ and $\Phi_{\theta}(\varsigma)$ are universal similarity functions. Other adiabatically conserved scalars should behave similarly to temperature since the transport is associated with eddies which are too large to be affected by molecular diffusion or viscosity. To agree with the log layer scaling, $\Phi_{m}(\varsigma)$ and $\Phi_{\theta}(\varsigma)$ should approach 1 for 
small $\zeta$. This requires $\Phi_{m}(\zeta)=\Phi_{\theta}(\zeta) \rightarrow 1$ at $\zeta \rightarrow 0$. The functional form of the universal stability functions for stable stratification $\zeta \gg 1$ should be $\Phi_{m} \sim \Phi_{\theta} \sim \varsigma$ since the turbulence is not affected by the distance to the surface.

From this theory it follows that the Richardson number $R i=\beta(\partial \bar{\theta} / \partial z) /(\partial \bar{u} / \partial z)^{2}$ monotonically increases with $\mathrm{s} z / L$ and at $z / L \rightarrow \infty$ has an asymptote maximum value of $R i_{c r}=\chi^{2} C_{\theta 1} k^{-1} C_{U 1}^{-2}$. This shows that the universal function range cannot exceed $R i>R i_{c r}$. This is a classical result which follows from the equation of kinetic turbulent energy balance accepted by Kolmogorov at the time when MO theory was formulated.

The stability functions in Equations 3-4 must be determined empirically. In the 1950-60s, several field experiments were conducted for this purpose over regions of flat, homogeneous ground with low, homogeneous roughness elements, culminating in the 1968 Kansas experiment. Businger et al. (1971) documented the universal functions for SBL, which are still accepted and widely used:

$$
\begin{gathered}
\Phi_{m}\left(\frac{z}{L}>0\right)=1+4.7 \frac{z}{L} \\
\Phi_{\theta}\left(\frac{z}{L}>0\right)=0.74+4.7 \frac{z}{L}
\end{gathered}
$$

The MO similarity theory as expressed by Equations 3-4 subject to the universal function Equations 5-6 when integrated from the roughness height $Z_{0}, Z_{1}$ to $Z$ gives the Monin and Obukhov (1954) similarity theory profiles for the mean wind and potential temperature

$$
\begin{gathered}
\bar{u}(z)=\frac{u_{*}}{k}\left(\ln \frac{z}{z_{0}}+4.7 \frac{z-z_{0}}{L}\right) \\
\bar{\theta}(z)-\bar{\theta}\left(z_{1}\right)=\theta_{*}\left(0.74 \ln \frac{z}{z_{1}}+4.7 \frac{z-z_{1}}{L}\right)
\end{gathered}
$$

Equations 7-8 and Equation 1, form a closed algebraic system of equations for $\theta_{*}, u_{*}$ and $L$. Its solution lead to the following quadratic equation for $u_{*}$

$$
\begin{gathered}
{\left[0.74 \ln \frac{z}{z_{1}} \ln \frac{z}{z_{0}}-\left(\ln \frac{z}{z_{0}}\right)^{2}\right] u_{*}^{2}+\left[\bar{u}(z) k\left(2 \ln \frac{z}{z_{0}}-0.74 \ln \frac{z}{z_{1}}\right)\right] u_{*}} \\
+\left[4.7\left(z-z_{0}\right) k^{2} \beta\left(\theta(z)-\theta\left(z_{1}\right)\right)-k^{2} \bar{u}^{2}(z)\right]=0
\end{gathered}
$$

The coefficients of the above quadratic equation are; $\mathrm{a}=\left[0.74 \ln \frac{z}{z_{1}} \ln \frac{z}{z_{0}}-\left(\ln \frac{z}{z_{0}}\right)^{2}\right]$

$$
\mathrm{b}=\left[\bar{u}(z) k\left(2 \ln \frac{z}{z_{0}}-0.74 \ln \frac{z}{z_{1}}\right)\right] \text { and } \mathrm{c}=\left[4.7\left(z-\mathrm{z}_{0}\right) k^{2} \beta\left(\theta(z)-\theta\left(z_{1}\right)\right)-k^{2} \bar{u}^{2}(z)\right]
$$

Negative discriminant given by $b^{2}-4 a c<0$, indicates all turbulence is suppressed in SBL. Therefore all data with negative discriminant are not valid for this calculation. Positive discriminant given by $b^{2}-4 a c>0$, indicates turbulence exist in the SBL. Zero discriminant is given by $b^{2}-4 a c=0$, indicates existence of turbulence in the SBL.

$\theta_{*}$, is solved from the following equation:

$$
\theta_{*}=\frac{u_{*}}{4.7 \kappa^{2} \beta\left(z-z_{0}\right)}\left[\bar{u}(z) \kappa-u_{*} \ln \left(\frac{z}{z_{0}}\right)\right]
$$

Using the experimental data one can calculate $u_{*}, \theta_{*}$ and $\mathrm{L}$ and subsequently the vertical profiles of the meteorological elements in the surface boundary layer.

The performance of the MoninObukhov similarity theoryin the SBL has been investigated for the wind velocity less than $6 \mathrm{~m} / \mathrm{s}$ and greater than $6 \mathrm{~m} / \mathrm{s}$ (Figures 3 and 4 ). These figures depict the dependence of $u_{*}$ on stability $(\Delta \theta)$. Also indicates that the MoninObukhov similarity theory gives realistic results of $u_{*}$ if the wind velocity 
is less than $6 \mathrm{~m} / \mathrm{s}$. In the analysis, in few cases wind velocity greater than $6 \mathrm{~m} / \mathrm{s}$ were observed in SBL (see Table 3 ) and the decision was to exclude such velocity.

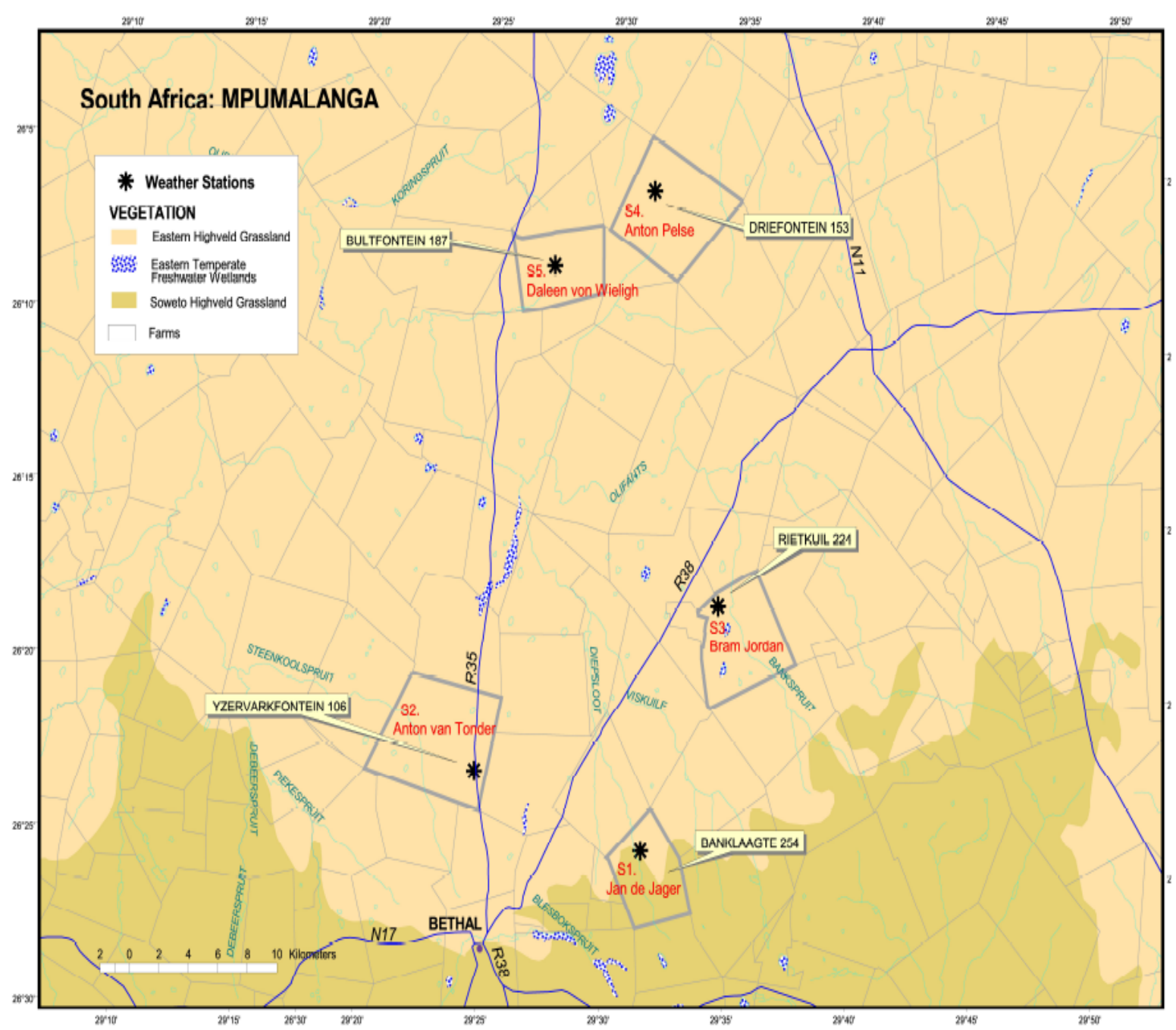

Figure 2. Location of the automatic meteorological stations in the experiment. Stars denote the weather stations; gray contours are farm boundaries; blue lines are significant roads. Farm names are given in red and farm addresses are within yellow boxes 


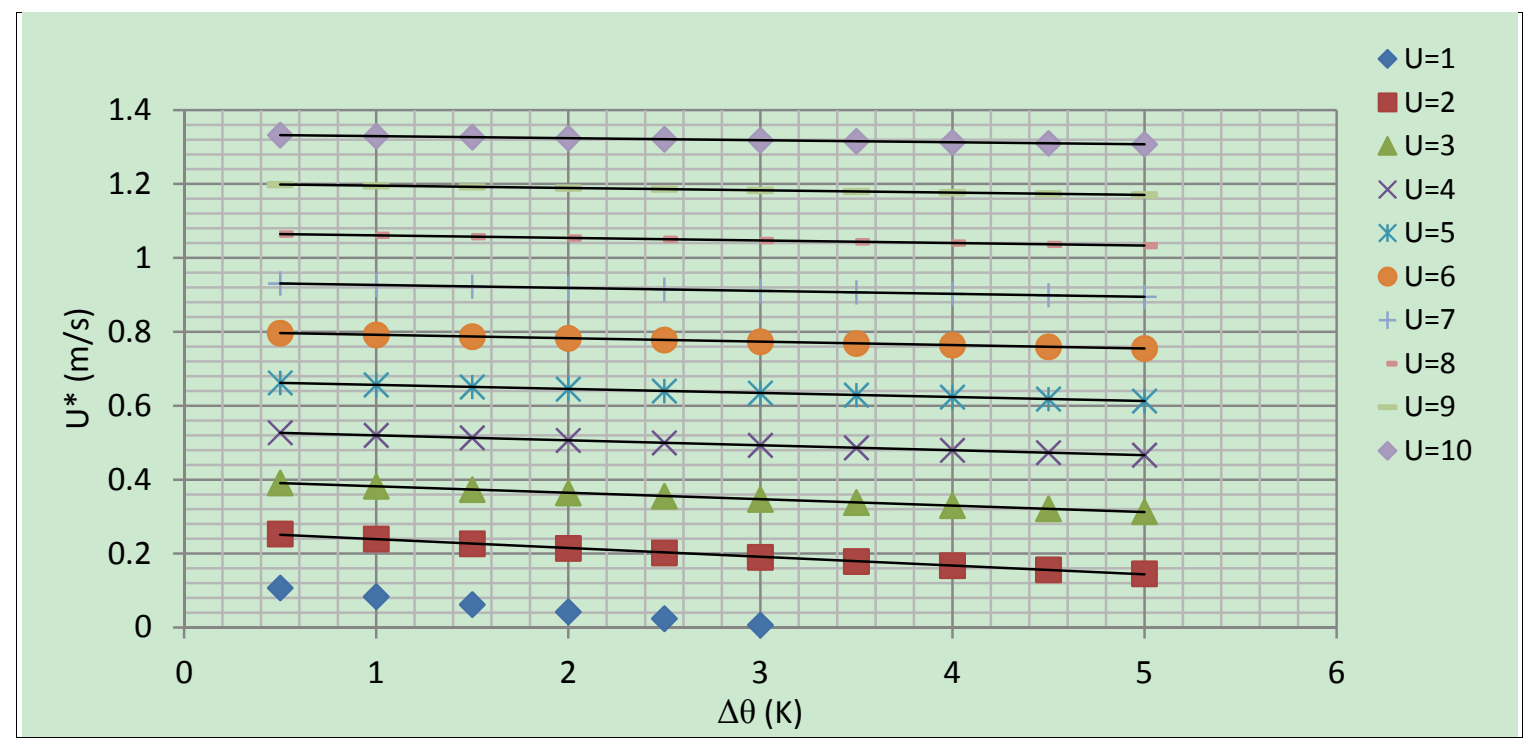

Figure 3. Variation of $\mathrm{u}^{*}(\mathrm{~m} / \mathrm{s})$ with $\Delta \theta(\mathrm{k})$ at different wind speed

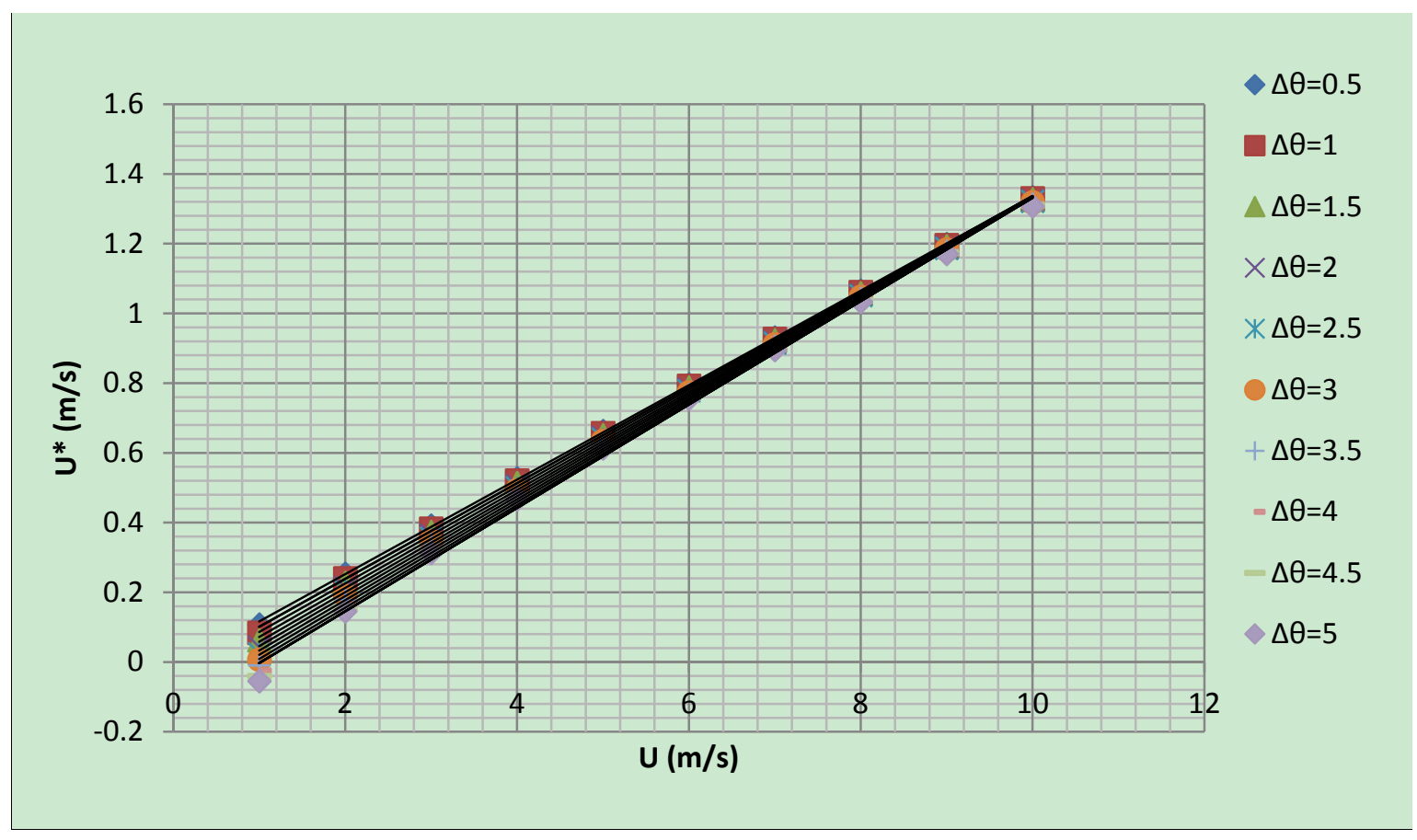

Figure 4.Variation of $\mathrm{u}^{*}(\mathrm{~m} / \mathrm{s})$ with wind speed at different $\Delta \theta(\mathrm{K})$

\section{Results and Discussion}

The Similarity theory discussed in the previous section, allow presentation of results for the surface layer characteristics (Obukhov length, momentum and heat fluxes) in the SBL over the Highveld Priority Area. Shown in Figure 5 are the average friction velocity (kinematic momentum flux) deduced from the similarity theory using data set collected from 2008 to 2010 . The calculated values of friction velocity $u_{*}$ shown in Figure 5 portrayed rather negligible values for the SBL with almost $82 \%$ of friction velocity having values in the range of $0<u_{*}<0.2(\mathrm{~m} / \mathrm{s})$. The dominant low values for the friction velocity is suggestive that the mechanical contribution to the surface layer turbulence was minimal which is consequent from the rather weak wind fields normally noticed in the SBL. This observation also suggests that active turbulence was non-existent in the SBL 
over Highveld Priority Area. Figure 5 also reveals that the distribution of turbulent momentum fluxes at the spatial scales between the stations is almost similar for category: $0<u_{*}<0.2$ and $0.2<u_{*}<0.4$. In Figure 6 are the average turbulent heat fluxes obtained in the SBL over the Highveld Priority Area. Low values of turbulent heat fluxes within the range of $0<\theta_{*}<0.2$ dominate at station 1 and 2 , and account for about $46-59 \%$ of all the cases observed. At station 3, 4 and 5, turbulent heat fluxes within the range of $0.2<\theta_{*}<0.4$ account for about $39-40 \%$ of all cases observed. This observation suggests that the magnitude of heat loss by the surface during the SBL is very smaller at station 1 and 2 than at station 3, 4 and 5, due to the altitude of the stations (see Table 1). Heat loss by the surface in the SBL is larger at the stations in high altitudes than at the stations in lower attitude. The Obukhov lengths plotted in Figure 7 suggests that the SBL over Highveld Priority Area is definitely seen as strong stable; almost $84 \%$ fall within the strong stable case category $0<L<16$ (Barthelmie, 1999). The spatial distribution of Obukhov length suggests that stronger stability cases at station 3, 4 and 5 account for about $84-89 \%$ and at station 1 and 2 account for about $78-82 \%$.

Figure 8 depicts the temporal variation of turbulent momentum flux in the range of $0<u_{*}<0.2(\mathrm{~m} / \mathrm{s})$. This low values of turbulent momentum fluxes dominate around 15-18 and 18-21 hours local time (GMT+2) then decreases as night progresses reaching their minimum percentage at 6-15 hours local time (GMT +2 ). Temporal variation of turbulent heat fluxes in the range of $0<\theta_{*}<0.2,0.2<\theta_{*}<0.4,0.4<\theta_{*}<0.6$, and $0.6<\theta_{*}<0.8$ are presented in Figure 9, 10, 11 and 12 respectively. Here more turbulent heat fluxes dominate at $15-18$ and 18-21 hours. This observation suggests that the magnitude of heat loss (radiative cooling) by the surface is strong at 15-18 and 18-21 hours and influence strong stability over Highveld Priority. These results also suggest that radiative cooling is stronger at night than in the day time SBL.

Figure 13 indicates temporal distribution of stability regimes as presented by the Obukhov length with a strong stability regime dominates at 15-18 and 18-21 hours. These observations are important for numbers of practical applications. For example numerical, dispersion and weather prediction modellers can use these realistic values of turbulent fluxes within the industrial areas over the Highveld to estimate the dispersion of the pollutants within the SBL. The existing temporal inter-station variability of $u_{*}, \theta_{*}$ and L (see Figures 8-13), suggests that when tracers cloud emitted in the SBL over HPA will be advected at different speeds. The differential advection stretches the tracer cloud causing it to spread longitudinally more quickly. Also the inter-station variability of $u_{*} \theta_{*}$ and $\mathrm{L}$ influences on creation of lateral gradients of tracer cloud (pollutant) concentration. This is then acted upon by lateral diffusion to accelerate the dilution of pollutant cloud. The combining impact of differential advection and lateral diffusion are the processes creating longitudinal spreading of tracer clouds (pollutants).

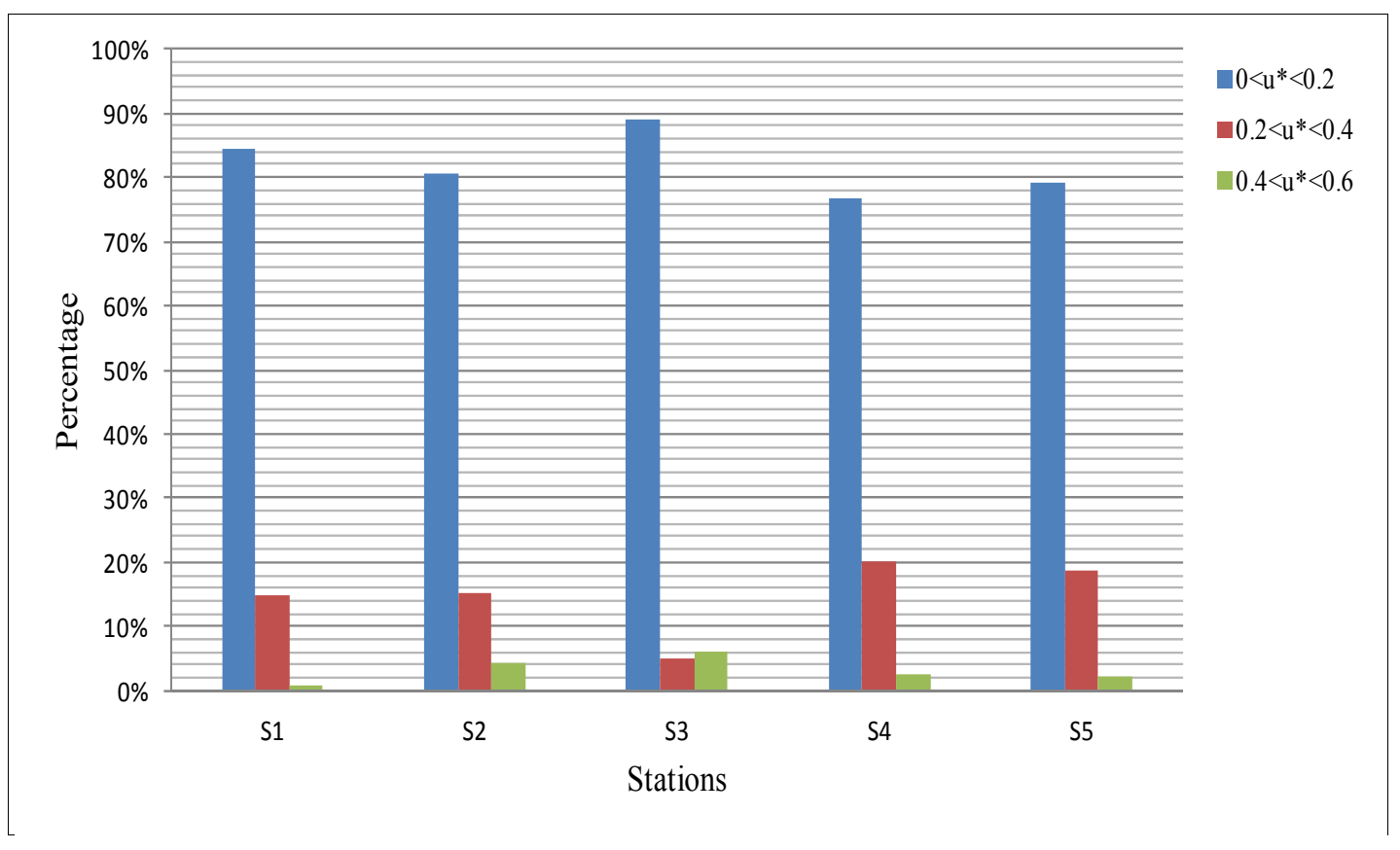

Figure 5. Spatial distribution of the turbulent momentum fluxes 


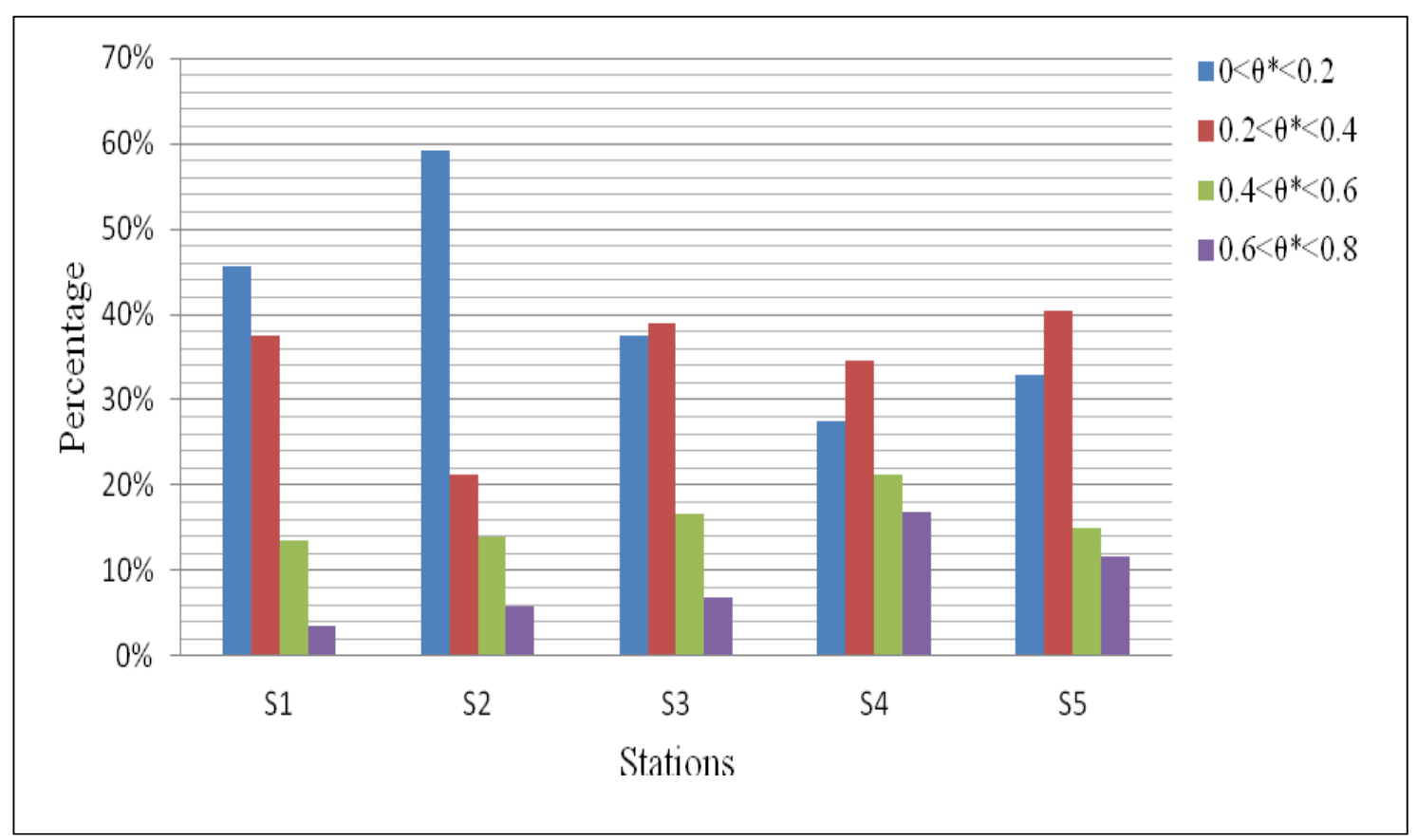

Figure 6. Spatial distribution of the turbulent heat fluxes

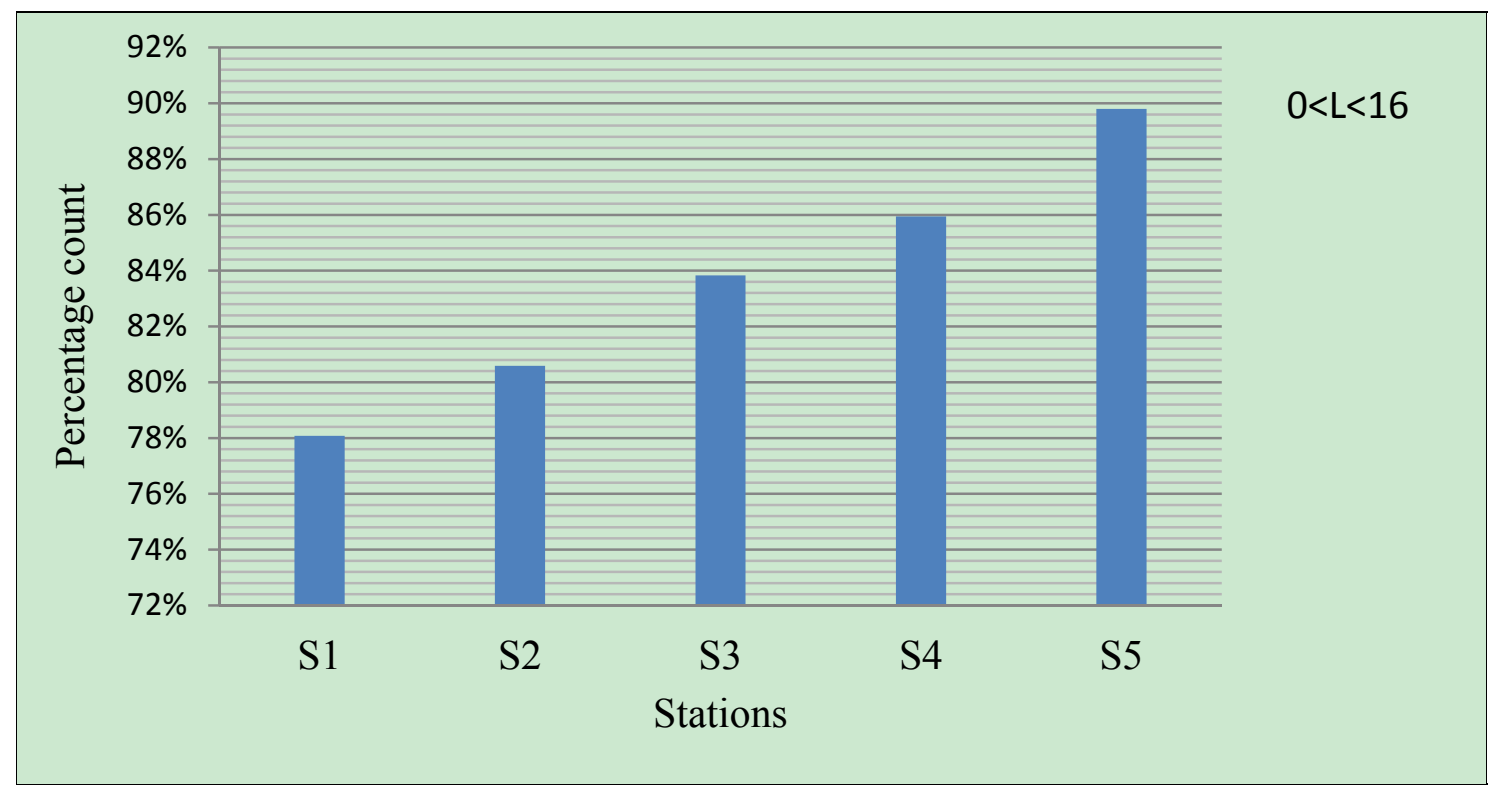

Figure 7. Spatial distribution of the average Obukhov length 


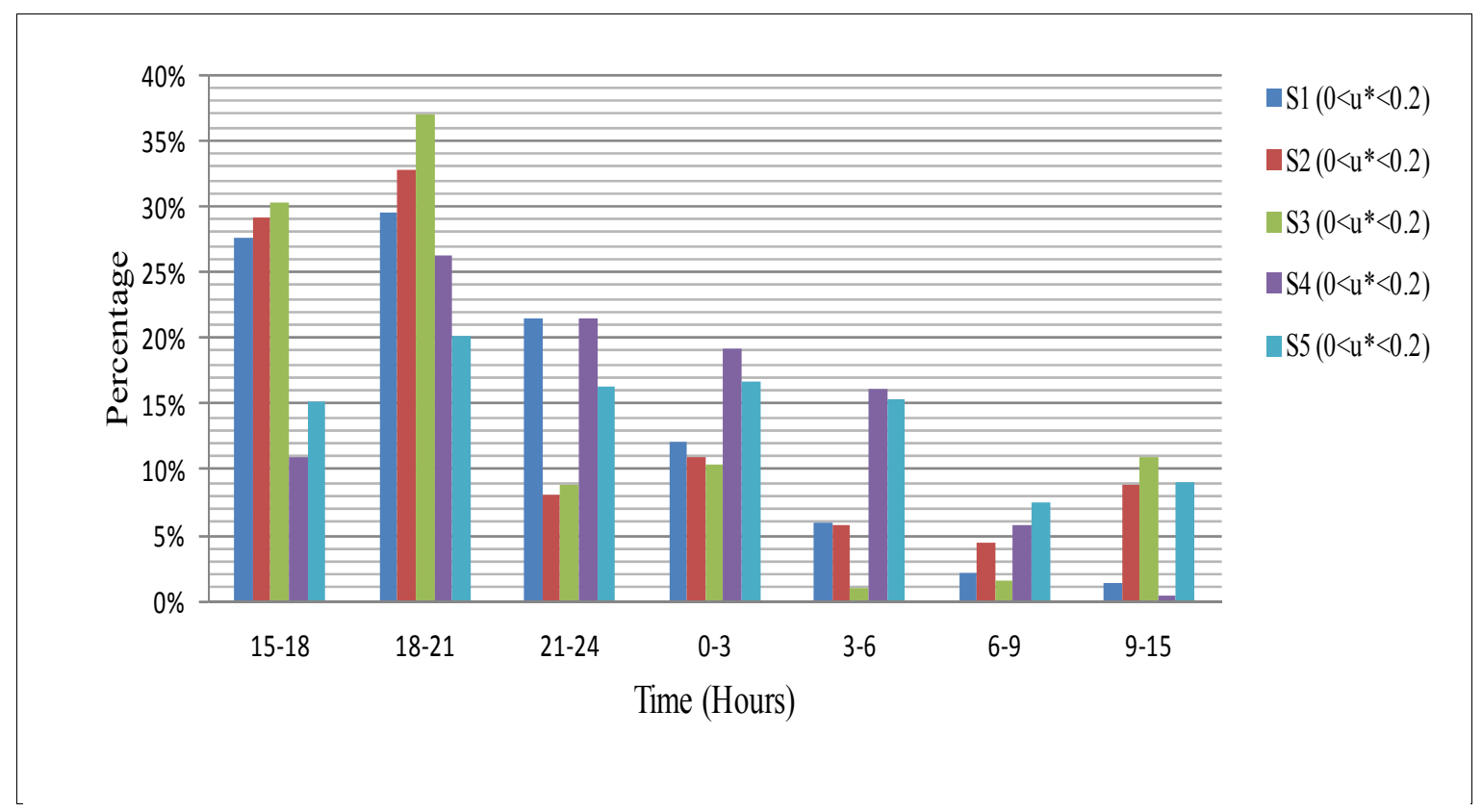

Figure 8. Temporal variation of the turbulent momentum fluxes in the range of $0<u_{*}<0.2$

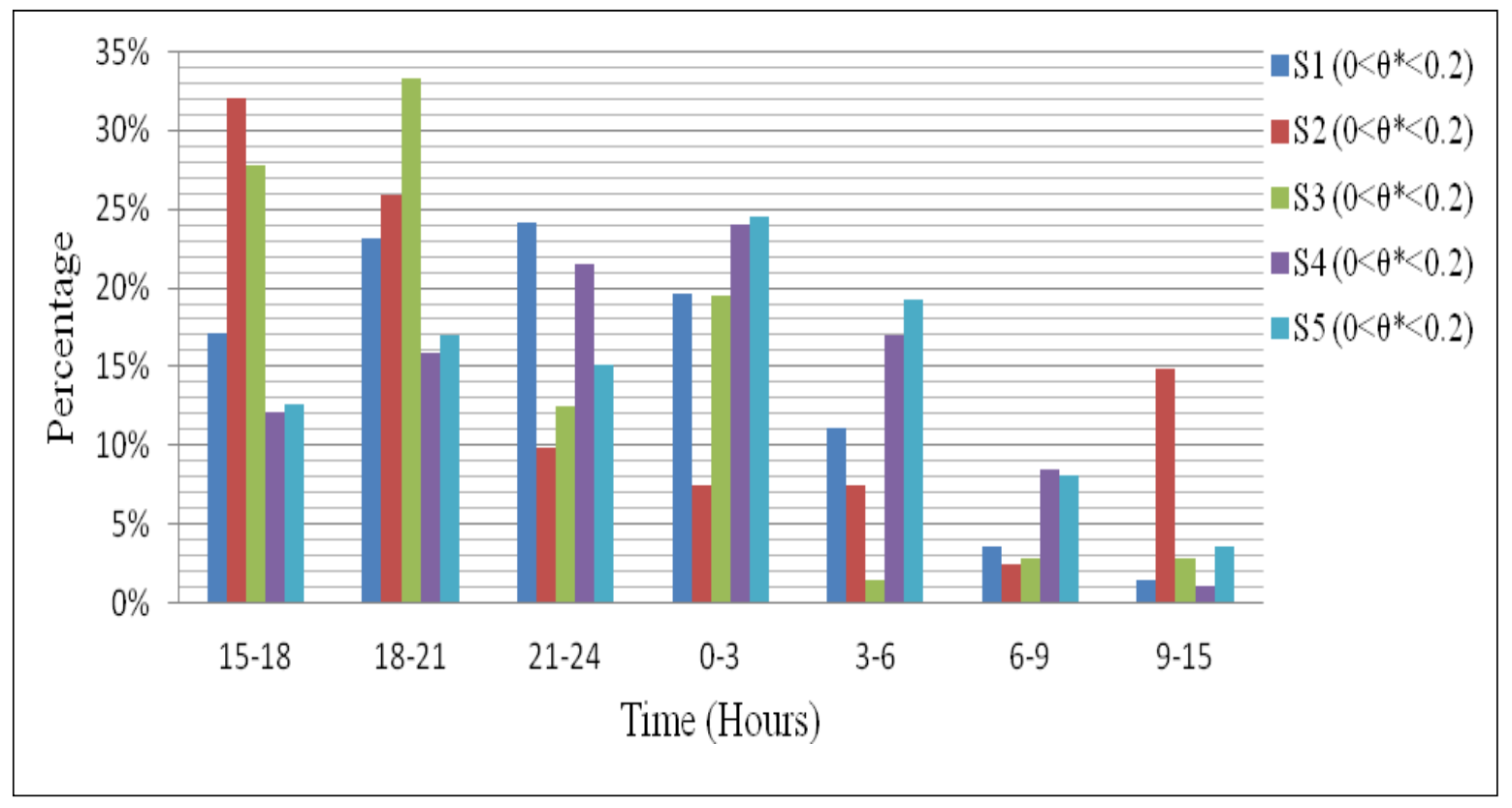

Figure 9. Temporal variation of the turbulent heat fluxes in the range of $0<\theta_{*}<0.2$ 


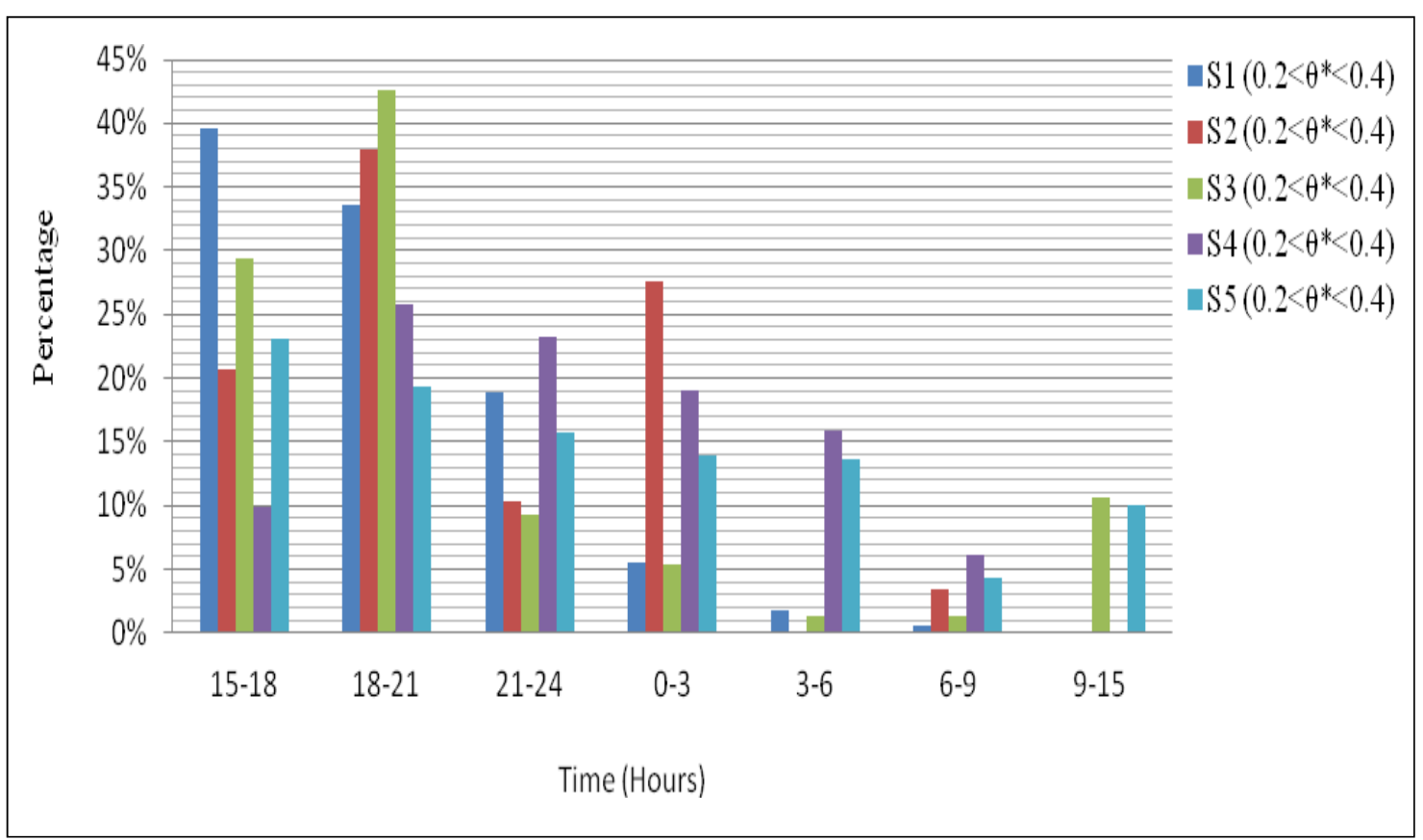

Figure 10.Temporal variation of the turbulent heat fluxes in the range of $0.2<\theta_{*}<0.4$.

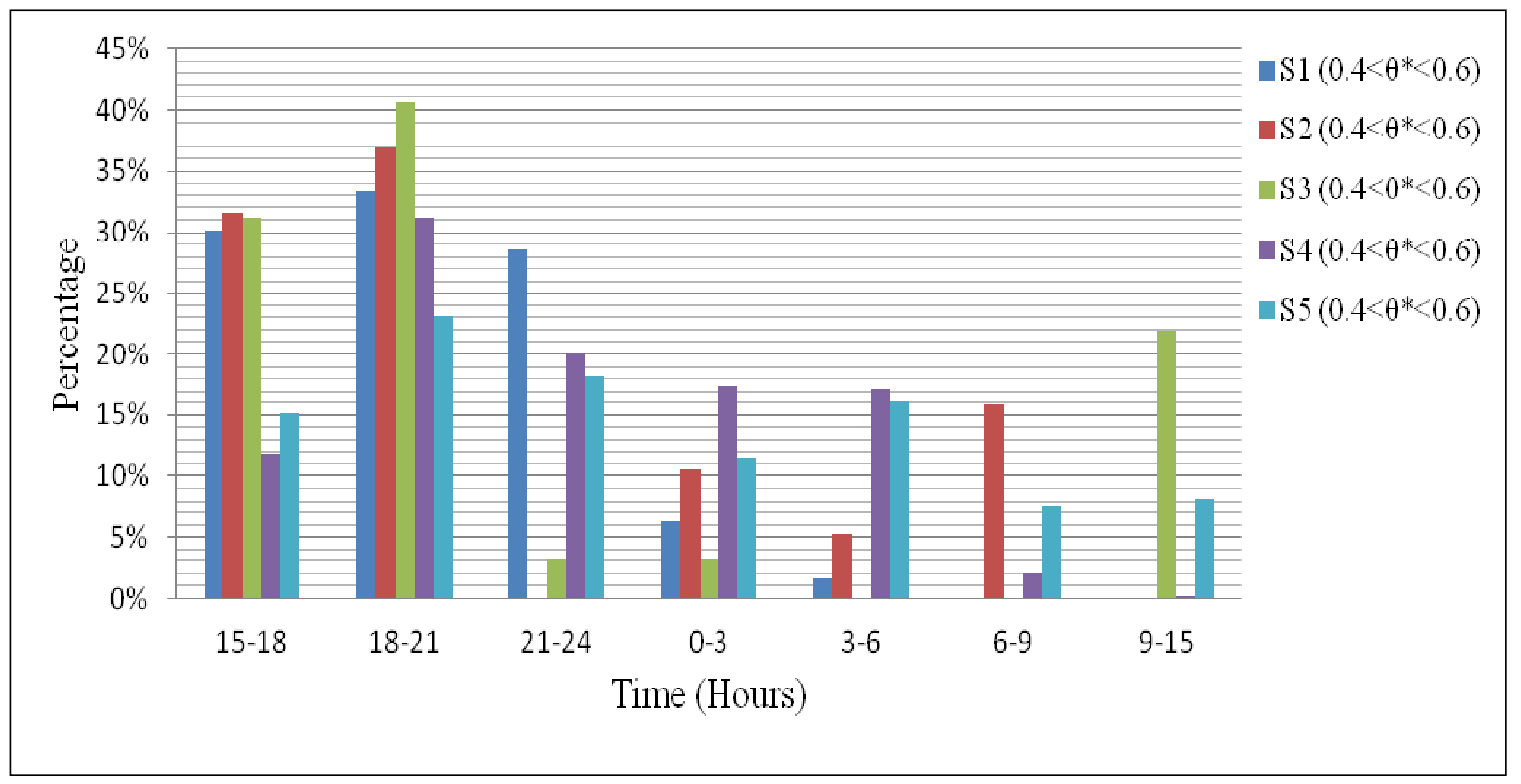

Figure 11. Temporal variation of the turbulent heat fluxes in the range of $0.4<\theta_{*}<0.6$ 


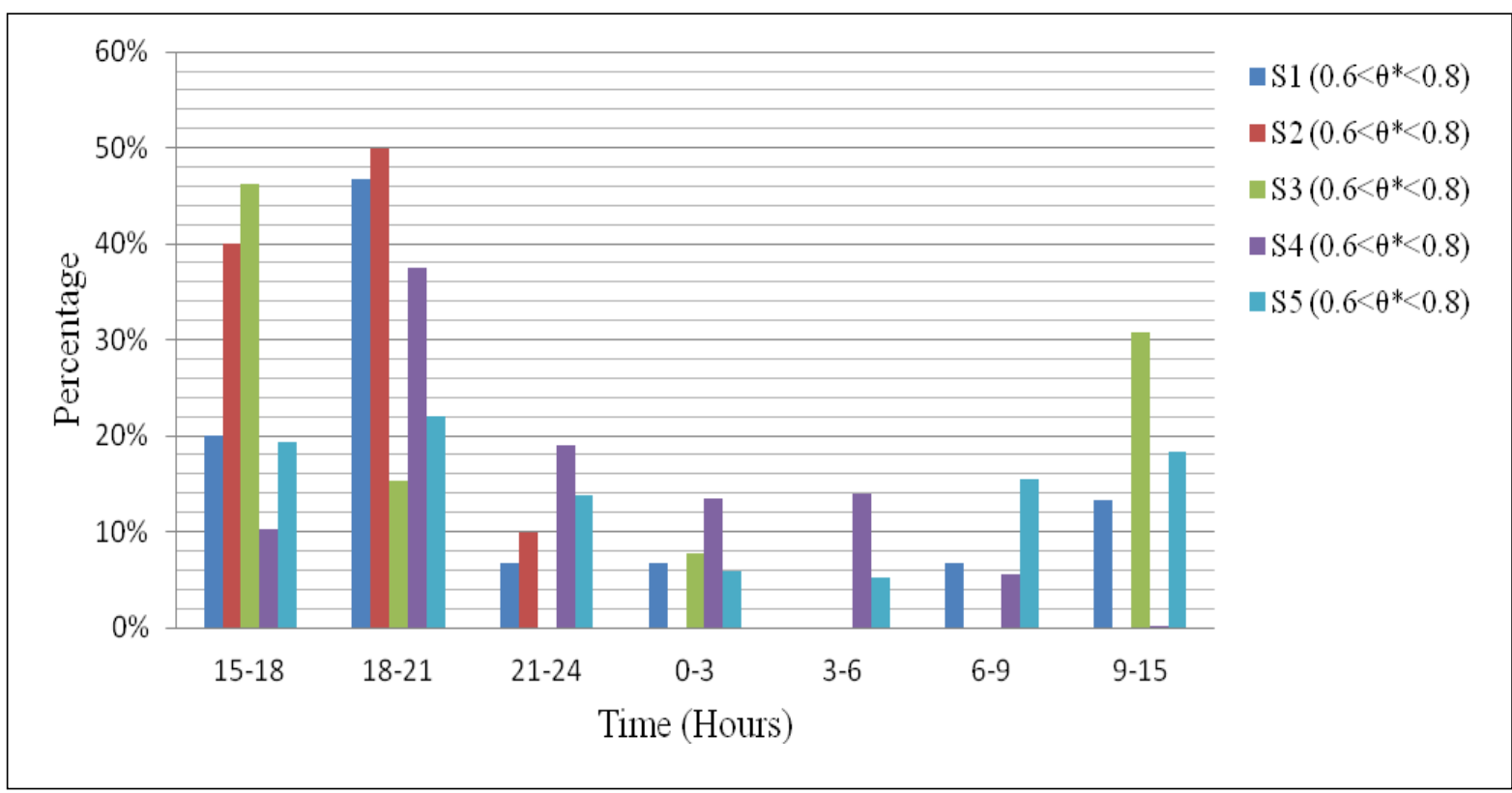

Figure 12. Temporal variation of the turbulent heat fluxes in the range of $0.6<\theta_{*}<0.8$

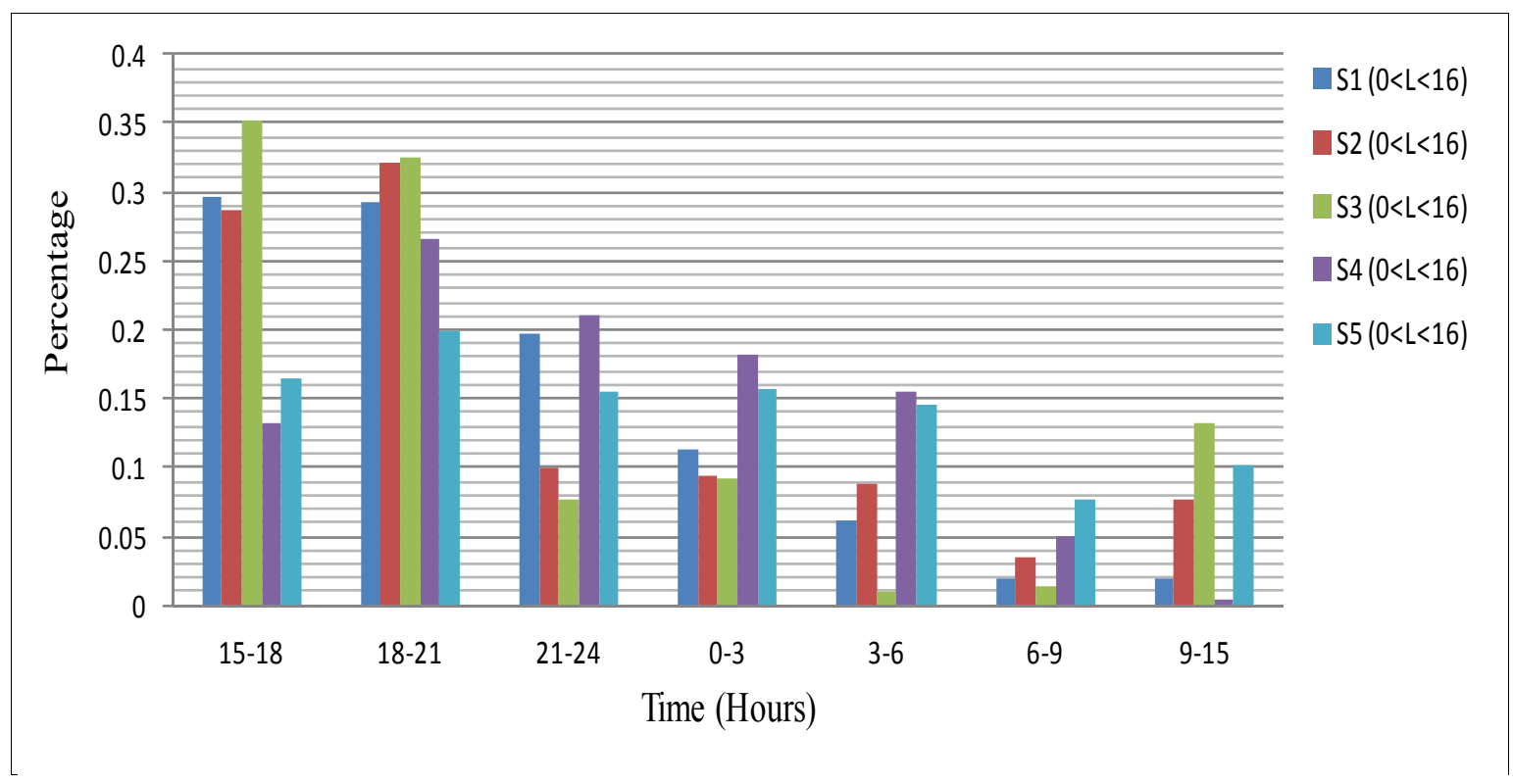

Figure 13. Temporal variation of the Obukhov length

\section{Conclusion and Recommendations}

The new generation or the advanced-type of operational air pollution models depends on surface layer parameters such as stability, surface stress and heat fluxes to estimate the dispersion of effluents within the boundary layer. This study provides the stability classes, momentum and heat fluxes calculated from the Monin-Obukhov similarity theory. The momentum fluxes show no significant spatial variation between stations but the heat fluxes and Obukhov length shows spatial variation between stations with stronger heat loss and strong stability at station 3, 4 and 5 than at station 1 and 2. The low values of Obukhov length (L) is suggestive that Highveld is dominated by strong stability regime. Other than low values of $\mathrm{L}$, small values of momentum and heat fluxes indicate the presence of strong stability regime. It is important here to mention that the 
probability of occurrence of air pollution episodes over Highveld region for emission from low level sources is very high since the dispersion effects by the mean wind flow is very limited due to the weak turbulent friction velocity and the existing strong stable condition. The letter does not support mixing in the SBL; it sometimes results on decoupling of the stable boundary layer from the surface, also lowers the SBL height since turbulence that carry the BL height at higher level are limited and occur intermittently. Then when pollutants are emitted from continuous sources under such atmospheric conditions will accumulates and affects the nearby populations. Temporal distribution of momentum and heat fluxes and Obukhov length indicates that large percent of momentum, heat fluxes and Obukhov length occur around 15-18 and 18-21 hours local time (GMT+2) then decreases as night progresses reaching their minimum values at 6-15 hours local time $(\mathrm{GMT}+2)$. These observations suggests that radiative cooling is stronger in the night time than day time SBL, stability is stronger in the night than day time SBL, momentum fluxes is smaller in the night time than day time SBL.

The observed temporal inter-station variability of $u_{*}, \theta_{*}$ and $\mathrm{L}$ (in Figures 8-13), suggests that when tracers cloud emitted in the SBL over HPA will be advected at different speeds. The differential advection stretches the tracer cloud causing it to spread longitudinally more quickly. Also the inter-station variability of $u_{*} \theta_{*}$ and L influences on creation of lateral gradients of tracer cloud (pollutant) concentration. This is then acted upon by lateral diffusion to accelerate the dilution of pollutant cloud. The combining impact of differential advection and lateral diffusion are the processes creating longitudinal spreading of tracer clouds (pollutants).

\section{References}

Barthelmie, R. J. (1999). The effect of atmospheric stability on coastal wind climates, Meteorol. Appl., 6, 39-47.

Bretherton, C. (2011). Lecture 5. The logarithmic sub layer and surface roughness.University of Washington, Washington. Retrieved from http://www.atmos.washington.edu/academics/classes/2011Q1/547/lect5.pdf

Businger, J. A., Wyngaard, J. C., Uzumi, Y., \& Bradley, E. F. (1971). Flux-profile relationship in the atmospheric surface layer. J. Atm. Sci., 28, 181-189.

Chiang, C. W., \& Nee, J. B. (2006). Boundary layer height by Lidar aerosol measurements at Chung-Li $\left(25^{\circ} \mathrm{N}\right.$, $\left.121^{\circ} \mathrm{E}\right)$. Proceeding of 23rd International Laser Radar Conference, 5O-6, 2006

Collett, K. S., Piketh, S. J., \& Ross, K. E. (2010). An assessment of the atmospheric nitrogen budget on the South African Highveld. South African J. of Sci., 106(5-6), 1-9.

Esau, I. N., Zilitinkevich, S. S., Djolov, G. D., \& Rautenbach, J. de W. C. (2010). A micro-meteorological experiment in the atmospheric boundary layer in Highveld region. IOP Conf. Series: Earth and Environmental Science, 13(2010)-012012. http://dx. Doi.org/10.1088/1755-1315/13/1/012012

Esau, I., Luhunga, P., Djolov, G. D., \& Zilitinkevich, S. (2012). Links between observedmicro-meteorologicalvariability and land-use patterns in the highveld priority area of South Africa. Meteorology and Atmospheric Physics, 118, 3-4, 129-142.

Eskom. (1994). Statistical yearbook for 1993. Eskom, Sandton, South Africa

Freiman, M. T., \& Piketh, S. J. (2003). Air transport into and out of the industrial Highveld region in South Africa. J. Applied Meteorol., 42, 994-1005.

Freiman, M. T., \& Tyson, P. D. (2000). The thermodynamic structure of the atmosphere over South Africa: Implications for water vapour transport. Water S. A., 26(2), 152-158.

Garratt, J. R. (1992). The atmospheric boundary layer. Cambridge university press.

Held, G., Scheifinger, H., Snyman, G. M., Tosen, G. R., \& Zunckel, M. (1996). The climatology and meteorology of the Highveld. Environmental Scientific Association, Cleveland, 144.

Holton, J. R. (2004). An introduction to Dynamic Meteorology (4th ed.). U.S.A: Elsevier Academic Press.

Jury, M. R., \&Tosen, G. R. (1989). Characteristics of the winter boundary layer over the, African Plateau: $26^{\circ}$ S. Boundary-Layer Meteorol, 49(1-2), 53-76.

Kolmogorov, A. N. (1941). Energy dissipation in locally isotropic turbulence. Doklady AN SSSR, 32(1), 19-21.

Laakso, L., Vakkari, V., Laakso, H.,Virkkula, A., Kulmala, M., Beukes, J. P., ... Kerminen, V. M. (2010). South African EUCAARI - measurements: a site with high atmospheric variability. Atmos. Chem. Phys. Discuss., 10, 30691-30729.

Monin, A. C., \& Obukhov, A. M. (1954). Fundamental laws of turbulent mixing in the atmospheric surface layer. Annals of the Geophysical Institute, AN USSR, 24(151), 163-187. 
Panofsky, H. A., \& Dutton, J. A. (1984). Atmospheric turbulence. Canada: John Wiley \& Sons, Inc.

Scheifinger, H., \& Held, G. (1997). Aerosol behaviour on the South African Highveld.Atmos. Environ., 31(21), 3497-3509.

Sivakumar, V., Tesfaye, M., Alemu, W., Moema, D., Sharma, A., Bollig, C., \& Mengistu, G. (2009). CSIR South Africa Mobile LIDAR-First scientific results : comparison with satellite, sun photometer and model simulations. South African J. of Science, 105, 449-455.

Steeneveld, G. J, \& Coauthors. (2008). Long term observations of Long Wave Radiative Flux Divergence in the Stable Boundary Layer. AMS Boundary Layer and Turbulence Conference, 9-13 June 2008, Stockholm.

Stefan, B. (2005). Thermal structure of the atmospheric boundary layer over the South African Mpumalanga Highveld. Climate Research, 29, 129-137.

Stull, R. B. (1988). An introduction to Boundary Layer Meteorology. Netherlands: Kluwer Academic Publishers.

Tennant, W. J., \& Hewitson, B. C. (2002). Intra-Seasonal Rainfall Characteristics and their Importance to the Seasonal Prediction Problem. Int. J. Climatol., 22, 1033-1048.

Thomas, D. S. G., Twyman, C., Osbahr, H., \& Hewitson, B. C. (2007). Adaptation to climate change and variability: farmer responses to intra-seasonal precipitation trends in South Africa. Climatic Change, 83, 301-322.

Tyson, P. D., \& Gatebe, C. K. (2001). The atmosphere, aerosols, trace gases and biogeochemical change in southern Africa: A regional integration. South African J. of Science, 97, 106-118.

Tyson, P. D., Kruger, F. J., \& Louw, C. W. (1988). Atmospheric pollution and its implications in the Eastern Transvaal Highveld (National Scientific Programmes Unit: CSIR, SANSP Report 150, pp. 123)

Van Gogh, R. G., Landenberg, H., Brassel, K., \& Danford, I. (1982). Dispersion climatology and characteristics of sulphur dioxide pollution in Eastern Transvaal Highveld (ATMOS/82/3, Atmospheric Science Division, CSIR, Pretoria, 117).

Venkatram, A, (1980). Estimating the Monin-Obukhov length in the stable boundary layer for Dispersion calculations, Boundary layer meteorology 19(1980)481-485D. Dordrecht, Holland and Boston, USA: Reidel publishing Co.

Wygaard, J. C. (1975). Modeling the planetary Boundary Layer-Extension to the stable case. Bound.-Layer Meteor., 9, 441-460.

Zilitinkevich, S. S., Elperin, T., Kleorin, N., \& Rogachevski, I. (2007). Energy and flux budge (EFB) turbulent closure model for stably flows, Part I: steady-state, homogeneous regimes. Atmospheric Boundary Layers, Springler, 11-36.

Zilitinkevich, S., \& Esau, I. N. (2005). Resistance and heat transfer laws for stable and neutral planetary boundary layers: old theory, advanced and reevaluated. Quart J Roy Meteorol Soc., 131, 3339-3356.

\section{Copyrights}

Copyright for this article is retained by the author(s), with first publication rights granted to the journal.

This is an open-access article distributed under the terms and conditions of the Creative Commons Attribution license (http://creativecommons.org/licenses/by/3.0/). 